\title{
Association between acculturation, obesity and cardiovascular risk factors among male South Asian migrants in the United Arab Emirates - a cross-sectional study
}

Syed M Shah ${ }^{1 *}$, Tom Loney ${ }^{1}$, Salma Al Dhaheri ${ }^{2}$, Hassan Vatanparast ${ }^{3}$, Iffat Elbarazi ${ }^{1}$, Mukesh Agarwal ${ }^{4}$, lain Blair ${ }^{1}$ and Raghib Ali ${ }^{1}$

\begin{abstract}
Background: Approximately 65\% of the United Arab Emirates (UAE) population are economic migrants from the low- and middle-income countries of South Asia. Emerging evidence suggests that expatriate populations from low or middle-income countries that migrate to high-income countries acculturate their lifestyle with the obesogenic behaviours of the host country. Previous research has focussed on migrant populations in the United States. The objective of this study was to assess the prevalence of obesity and explore the relationship between years of residency (surrogate measure for acculturation) and obesity among South Asian (from India, Pakistan and Bangladesh) male immigrants residing in the UAE.
\end{abstract}

Methods: A random sample of 1375 males was recruited from a mandatory residency visa health screening centre in Abu Dhabi (UAE). Employing a cross-sectional design, participants completed an interviewer-led adapted version of the World Health Organisation STEPS questionnaire, and anthropometric and blood pressure measurements were collected. Glycated haemoglobin ( $\mathrm{HbA1c}$ ) was measured in a random sub-sample $(n=100)$. Logistic regression was used to determine risk factors for being classified as obese, and to assess the relationship between years of residency and adiposity.

Results: The overall prevalence of body mass index-derived overweight and obesity estimates and waist-to-hip-derived central obesity rates was 615 (44.7\%) and 917 (66.7\%) males, respectively. Hypertension was present in 419 (30.5\%) of the sample and diabetes in 9 (9.0\%) of the sub-sample. Living in the UAE for six to 10 years or more than 10 years was independently associated with being classified with central obesity (adjusted odds ratio [AOR] 1.63 95\% confidence intervals [CI] $1.13-2.35, p<0.008$; AOR $1.9595 \% \mathrm{Cl} 1.26-3.01, p<0.002$; respectively) compared to residing in the UAE for one to five years.

Conclusions: Our study revealed a high prevalence of overweight, central obesity and hypertension amongst a young South Asian male migrant population in the UAE. Study findings suggest a diminished 'Healthy Migrant Effect' with increased years of residency possibly due to greater acculturation and a transition in lifestyle behaviours. Health initiatives targeting the maintenance of a healthy body size, coupled with regular assessments of glucose control and blood pressure are urgently required in this population.

Keywords: Acculturation, Adiposity, Cardiovascular diseases, Obesity, Transients and migrants, United Arab Emirates

\footnotetext{
*Correspondence: syeds@uaeu.ac.ae

'Institute of Public Health, College of Medicine and Health Sciences, United

Arab Emirates University, Al Ain, United Arab Emirates

Full list of author information is available at the end of the article
} 


\section{Background}

According to the World Health Organization (WHO), non-communicable chronic diseases (NCDs) such as cardiovascular disease, cancer, chronic respiratory disease and diabetes cause $60 \%$ of all deaths globally [1]. By 2030, the global cost of NCDs will reach $\$ 47$ trillion [2]. Moreover, $80 \%$ of this mortality occurs in low- and middle-income countries [1]. Numerous studies have shown that South Asian populations (e.g. India, Pakistan, Bangladesh, Sri Lanka, and Nepal) contribute the highest proportion of the global burden of cardiovascular diseases [3,4]. In addition, risk factors for NCDs such as central obesity, hypertension and insulin resistance develop at a lower age in South Asians than other ethnic groups [5,6]. Moreover, South Asian immigrants overseas have a three to five-fold increase in the risk for myocardial infarction and cardiovascular death compared with other ethnic groups $[7,8]$.

Obesity is a major contributor to cardiovascular disease and hence, it is a leading risk factor for adult mortality in both developed and developing countries [9]. People from Asia have a higher risk of type 2 diabetes and cardiovascular disease at lower levels of body mass index (BMI) [10]. Thus, in South Asians migrants, substantially lower obesity levels show an equivalent amount of dyslipidemia and dysglycemia when compared to BMI-matched White Europeans [11]. Furthermore, immigrant populations relocating from low- and medium-income countries to a higher income country are at a greater risk of weight gain, particularly males [12]. The 'Healthy Migrant Effect' is a phenomenon observed in epidemiology where newly arrived migrants tend to be healthier than the host population due to a positive selection bias that a formal migration process and residency health checks require. Emerging evidence suggests that the 'Healthy Migrant Effect' may diminish with increased years of residency due to lifestyle and nutrition transition associated with acculturation i.e. the complex, gradual exchange of immigrants' original attitudes and behaviours to the obesogenic behaviours in the host culture. A recent systematic review synthesised data from nine cross-sectional studies of Mexican, El Salvador, Puerto Rico, Thailand/Laos Hmong, Korean and Soviet Union immigrants residing in the United States. Findings showed a positive association between higher acculturation and body mass index in males [12].

In the past 40 years, the United Arab Emirates (UAE) has achieved significant economic and industrial growth. The rising affluence of the UAE population with its accompanying increased caloric intake, and decreased physical activity has rapidly increased the prevalence of obesity $[13,14]$. Consequently, the UAE ranks sixth in a recent indexing of the top 10 'heaviest' countries in the world (ranking determined by number of adults per tonne of human biomass) [15]. The expatriate population accounts for approximately 89 percent of UAE population and approximately two-thirds of all the immigrants are South Asian [16]. The UAE population has increased substantially over the past four decades and this is primarily due to the high net inward migration of expatriate workers from South Asia (UAE population estimates: 287,000 in 1971, 4.1 million in 2005, 8.3 million in 2010). Abu Dhabi is the largest of the seven UAE emirates with an estimated population of 2.3 million, of which over half of the population are expatriate males aged 20-59 years. All expatriate workers seeking employment in the UAE are required by federal law to undergo a health and communicable disease screening test at a government visa screening centre before receiving a residency permit. In 2012, 181,231 male immigrants visited the visa screening centre (Disease Prevention and Screening Centre, Preventive Medicine Department, Health Authority Abu Dhabi) in the city of $\mathrm{Al}$ Ain (second largest city in Abu Dhabi Emirate) to obtain or renew a visa [17]. Majority of these workers are low-paid, semi- or unskilled, without long-term job security, living alone or in shared accommodation, and separated from their families, they often suffer from stress, anxiety and depression [18]. A dearth of information exists on the prevalence of overweight and obesity among South Asian immigrants in the UAE. The aim of this study was to assess the prevalence of obesity and explore the relationship between years of residency (surrogate measure for acculturation) and obesity among South Asian (from India, Pakistan and Bangladesh) male immigrants residing in the UAE.

\section{Methods}

\section{Study design and ethics}

The study used a cross-sectional descriptive design. Ethical approval was obtained from both the Al Ain Medical District Human Research Ethics Committee, and the Abu Dhabi Health Services Company's Research Committee.

\section{Study sample and setting}

The study took place between January and June 2012 . All expatriate workers seeking employment in the UAE are screened for communicable diseases, such as tuberculosis (by chest X-ray) and human immunodeficiency virus (by serology), before acquiring residence status. We invited every third migrant worker (from India, Pakistan and Bangladesh) who visited the Preventive Medicine Department in $\mathrm{Al}$ Ain for a health examination to obtain a new or renew an existing visa to participate in the study. Of the 1800 eligible participants, 1375 (76.4\% response rate) participated in the study.

\section{Measures \\ Health and lifestyle questionnaire}

The informed consent forms and questionnaires used in the study were written in the native languages of the 
workers, i.e., Urdu and Bangali. The questionnaire was initially developed in English, and then forward translated into Urdu and Bengali. It was then pretested in the pilot study and finalised after necessary amendments. The questionnaire comprised an adapted version of WHO STEPwise approach to Surveillance, "STEPS", developed by WHO for the measurement of NCD risk factors at the country level [19]. Due to the low literacy rates among the South Asian expatriate population in the UAE, all questionnaires were completed during an interview with a native Urdu or Bengali speaking researcher. The questionnaire interview collected information that included demographic characteristics, personal and family and disease history, history of current and past consumption of cigarettes, alcohol, other forms of tobacco (history of exposure to second hand tobacco), home country residence type (rural, urban, semi-urban), occupation, monthly salary in UAE dirhams (AED), years of residency in the UAE, accommodation type, and physical activity. Information related to the diagnosis and treatment history of hypertension and diabetes was also collected.

We classified monthly earning into bottom quartile (AED <900 per month), second quartile (AED 900 to $<1200$ ), third quartile (AED 1200 to 2000), and top quartile ( $>2000$ ). Using STEPS [19] questions on tobacco use, we classified subjects as current smokers if they answered yes to the question: "Do you smoke cigarettes daily?". Former smokers were defined if they had ever smoked at least 100 cigarettes during their lifetime. Ever smokers included current and former smokers. The variable relating to alcohol consumption was based on the STEPS question: "Did you drink any alcohol during the last 12 months?" The variables used for the analysis were current smoking and alcohol consumption during the last year. Information on physical activity was obtained using the International Physical Activity Questionnaire (IPAQ-short version) which measures the frequency (days per week), and duration (minutes per day) of moderate- and vigorous-intensity physical activity, in bouts of at least 10 minutes during the past 7-day period, globally in all contexts of daily life [20]. The IPAQ also assesses the time spent walking ( $\geq 10$ minutes duration) during the past 7 days and duration of walking within a given day in the last seven days was recorded to identify people who walked for at least 30 minutes each day.

\section{Anthropometric and blood pressure measurements}

Researchers were trained using a standard protocol to obtain anthropometric measurements. Body mass was measured (to the nearest $0.1 \mathrm{~kg}$ ) using a calibrated electronic scale equipped with a mounted stadiometer that measured height to the nearest $0.1 \mathrm{~cm}$ (SECA Hamburg, Germany). Body mass and height measurements were completed with the participant wearing light clothing without shoes and standing motionless. Waist and hip circumference were measured using a flexible nonstretch nylon tape measure (SECA Hamburg, Germany) with subjects wearing light clothing. Waist circumference was measured midway between the lower rib margin and the top of the iliac crest at the end of a gentle expiration to the nearest $0.1 \mathrm{~cm}$. Hip circumference was measured at the point of maximal protrusion of the gluteal muscles also to the nearest $0.1 \mathrm{~cm}$. Body mass index (BMI) was calculated as body mass in kilograms divided by height in metres squared. The WHO cut-offs were used to classify subjects as overweight $\left(25.0-29.9 \mathrm{~kg} / \mathrm{m}^{2}\right)$ or obese $\left(30.0 \mathrm{~kg} / \mathrm{m}^{2}\right)$ [21]. Waist circumference (WC) $\geq$ $94.0 \mathrm{~cm}$ and waist-to-hip ratio (WHR; waist in $\mathrm{cm} / \mathrm{hip}$ circumference in $\mathrm{cm}$ ) $\geq 0.90$ was used to define central obesity [22].

We followed 1999 World Health Organization/International Society of Hypertension guidelines to measure blood pressure [23]. Following 10 minutes of rest in a seated position, resting brachial blood pressure was measured with a calibrated automated sphygmomanometer (Omron HEM-705cp Intellisense Blood Pressure Monitor). Triplicate measurements were taken, three minutes apart on the right arm, and the mean of the last two readings was used for analyses. We classified participants as hypertensive if they had a measured systolic blood pressure above 140 , diastolic blood pressure above 90 , or if they reported taking medications that treat hypertension [24]. In addition, we collected a non-fasting venous blood sample to measure glycated haemoglobin (HbA1c) levels in a random subsample $(n=100)$ of the study population. The WHO cutoff of $\mathrm{HbA} 1 \mathrm{c} \geq 6.5 \%$ was used to indicate the presence of diabetes mellitus in the sub-sample.

\section{Statistical analysis}

Data files were created in Microsoft Access software. After cleaning and processing, data were imported into Stata SE version 11.0 (StataCorp LP, College Station, TX) for analysis. In descriptive analyses, percentages means and $95 \%$ confidence intervals (CI) were calculated. Chisquared test were conducted for categorical variables and analyses of variance was used for continuous variables. We used bivariate and multivariate models and for the logistic regression model we used a forward selection stepwise process to examine the association between sociodemographic, lifestyle and acculturation (indexed by years of residency) with the odds of overweight and obesity (based on BMI categories) and central obesity (waistto-hip ratio). Alpha was set at 0.05 . In our multivariable model we used age and income as continuous variable.

We also evaluated the effects of acculturation on other cardiovascular risk factors i.e. hypertension, diabetes and smoking. Participants who either self-reported doctordiagnosed diabetes or who were taking medications that 
treat diabetes or their $\mathrm{A} 1 \mathrm{C}$ level was greater or equal to 6.5 were classified as diabetes.

\section{Results}

Out of 1800 eligible participants 1375 (76.4\% response rate) participated in the study. Of the participants 433 were Indian, 383 were Pakistani and 559 were Bangladeshi. The mean age of the study population was 34.0 (95\% CI: 33.4, 34.5) years. Table 1 shows the general characteristics of the study population. Compared to Indian and Pakistani counterparts, Bangladeshi males were younger. The overall monthly average income in AED ( 1 USD $=3.7$ AED) was 1828 (95\% CI 1722, 1944). A high proportion of Bangladeshi subjects (60.4\%) earned less than 1000 AED per month compared to their Indian (20.6\%) and Pakistani $(32.3 \%)$ counterparts. Bangladeshi subjects were also less educated. Only $13.5 \%$ had college or university level education compared to Indians (31.7\%) and Pakistanis (16.4\%). Of the study participants, 68\% (95\% CI 66.1, 71.1) had migrated from rural villages in their home country. Overall, the majority (70\%) of subjects were married with on average three children. Nearly all (85\%) of those who were married lived away from their families. Half (52.2\%) of the study sample shared a rented accommodation with others while the remainder lived with their sponsor (13.4\%), in a single accommodation (11.1\%), in labour camps $(12.2 \%)$ or with family members (11.1\%). Over half $(55.1 \%)$ of participants had been living in UAE for more than six years. The most common occupational categories were driver (23.1\%), labourer (17.1\%), agricultural worker (17.1\%), construction worker (12.5\%) and salesman (5.7\%).

A higher proportion of Bangladeshi subjects (23.2\%) reported a family history of hypertension compared to Indians (14.8\%) and Pakistanis (15.0\%). A family history of diabetes was significantly more prevalent among Indians (15.9\%) compared to Pakistanis (8.1\%) and Bangladeshi (8.9\%) participants. Indians had a higher mean BMI $(31.5 \mathrm{~kg} /$ $\left.\mathrm{m}^{2}\right)$ compared to Pakistanis $\left(26.6 \mathrm{~kg} / \mathrm{m}^{2}\right)$ and Bangladeshis $\left(26.2 \mathrm{~kg} / \mathrm{m}^{2}\right)$. Bangladeshis had lower waist circumference $(85.6 \mathrm{~cm})$ and waist-to-hip ratio $(0.92 \mathrm{~cm})$ but reported a high rate of smoking (49.1\%) as compared to their Indian (34.3\%) and Pakistani (35.8\%) counterparts. Overall, 9.0\% of the sub-sample $(\mathrm{n}=99)$ were diabetic $(\mathrm{HbA1c} \geq 6.5 \%)$ and most of these reported having a physician diagnosis of diabetes. The prevalence of hypertension was $30.5 \%$ despite this being a young population of South Asian males. Nearly two-thirds (61.6\%) of the sample reported that they had never had their blood pressure measured. Among the study population, $44.4 \%$ of participants with diabetes and $76.0 \%$ of those with hypertension were not aware of their status. Overall a small proportion of the study participants reported moderate $26.7 \%$ (95\% CI 24.4 - 29.1) and vigorous, $18.2 \%$ (95\% CI 16.1 - 20.2) physical activity.
Self-reported vigorous and moderate physical activity was particularly low among drivers $(13.6 \%, 14.2 \%)$, shopkeepers and business men (13.3\%, 15.0\%), and tailors $(4.3 \%, 7.1 \%)$.

The overall crude prevalence of overweight and obesity in South Asian immigrants were 35.4\% (95\% CI 32.8\%, $37.9 \%$ ), and 9.4\% (95\% CI 9.2\%, 9.5\%), respectively. The crude prevalence of central obesity was $63.4 \%$ (95\% CI $60.8 \%, 65.9 \%)$. The crude prevalence of overweight and obesity was highest among Pakistanis, 52.5\% (95\% CI $47.3 \%, 57.5 \%$ ), followed by Indians, $47.4 \%$ (95\% CI 42.7\%, 52.2\%) and Bangladeshis, 37.4\% (95\% CI 33.4\%, 41.6\%). The overall crude prevalence of central obesity varied by nationality, $66.7 \%$ (95\% CI 62.8\%, 71.1\%) in Indians, $64.7 \%$ (95\% CI 59.7\%, 69.5\%) in Pakistanis, and 59.9\% (95\% CI $55.7 \%, 64.0 \%)$ in Bangladeshis.

Figure 1 illustrates the prevalence of underweight, normal weight, overweight and obesity by the duration of residency in South Asian immigrants. The prevalence of underweight decreased from $8 \%$ among those who had been in UAE for up to five years, to $1 \%$ among those who had been in UAE for more than 10 years. Prevalence of overweight and obesity was significantly $(p<0.05)$ higher (62\%) among those who had been in UAE for more than 10 years.

Table 2 presents the prevalence of overweight, obesity and central obesity and the factors significantly $(p<0.05)$ associated with being overweight or obese (BMI $\geq 25.0$ ). In un-adjusted analyses these factors included nationality, greater age, greater monthly salary, education, working as a driver, salesman, office worker, having a business or working as shop-keeper, or tailor, type of current accommodation, urban residence in their country of origin, being married, longer duration of residency in UAE and being hypertensive.

Table 3 shows the results of multivariate adjusted analyses. The factors independently and significantly associated with being overweight or obese included working as a driver, shop keeper or tailor, having a college or university level education, living in UAE for 6 to 10 years or more than 10 years and having hypertension. The factors independently and significantly associated with central obesity included greater age, working as a driver, businessman or shop-keeper, living in UAE for 6 to 10 years or more than 10 years, and having hypertension. The prevalence of overweight and obesity was extremely high among males who had been living in the UAE for more than five years and working in sedentary occupations (overall 77.4\%; 75.0\% among drivers, 86.7\% among shop keepers and business men, $70.6 \%$ among tailors). In addition, the prevalence of central obesity was also high in this group (overall 87.5\%; 86.9\% among drivers, 93.3\% among shopkeepers and business men, $82.3 \%$ among tailors). We also evaluated the effects of acculturation on 
Table 1 Characteristics of the South Asian Immigrants in Abu Dhabi, UAE 2012

\begin{tabular}{|c|c|c|c|}
\hline Characteristics & $\begin{array}{l}\text { India }(n=433) \\
\text { Mean }( \pm S D)\end{array}$ & $\begin{array}{l}\text { Pakistan }(n=383) \\
\text { Mean }( \pm S D)\end{array}$ & $\begin{array}{l}\text { Bangladesh }(n=559) \\
\text { Mean }( \pm S D)\end{array}$ \\
\hline Age (mean) years & $36.3( \pm 10.1)$ & $34.8( \pm 10.7)$ & $31.7( \pm 8.5)$ \\
\hline \multicolumn{4}{|l|}{ Education (\%) } \\
\hline None & 3.1 & 23.9 & 12.9 \\
\hline Primary or middle & 23.3 & 31.4 & 46.0 \\
\hline Secondary or high school & 36.9 & 28.3 & 27.6 \\
\hline College or university & 36.7 & 16.4 & 13.5 \\
\hline Income in Emirati Driham (AED) per month, median & 1500 & 1500 & 1000 \\
\hline Immigrated from a rural village (\%) & 64.3 & 56.7 & 83.2 \\
\hline Married (\%) & 78.5 & 75.3 & 60.1 \\
\hline Do not live with immediate family (\%) & 88.6 & 88.4 & 81.0 \\
\hline \multicolumn{4}{|l|}{ Type of accommodation (\%) } \\
\hline Shared with non-relatives & 51.4 & 41.1 & 58.6 \\
\hline Shared with family & 10.5 & 15.0 & 7.8 \\
\hline Single accommodation & 13.3 & 11.1 & 8.9 \\
\hline Live with sponsor & 13.3 & 16.7 & 12.2 \\
\hline Live in a labor camp & 11.5 & 16.1 & 12.4 \\
\hline Years in UAE (mean) & $10.3( \pm 8.6)$ & $11.7( \pm 9.9)$ & $8.2( \pm 6.8)$ \\
\hline \multicolumn{4}{|l|}{ Occupation (\%) } \\
\hline Driver & 21.5 & 33.9 & 19.2 \\
\hline Laborer & 14.1 & 12.8 & 20.3 \\
\hline Construction worker & 12.6 & 8.3 & 13.1 \\
\hline Agriculture worker & 8.2 & 25.0 & 20.5 \\
\hline Salesman & 12.6 & 3.1 & 3.3 \\
\hline Professional, office worker & 10.8 & 6.7 & 3.6 \\
\hline Business shop keeper & 5.4 & 4.2 & 4.0 \\
\hline Hospitality worker (cook, waiter) & 8.2 & 0.8 & 6.5 \\
\hline Tailor & 3.6 & 1.9 & 6.8 \\
\hline Other & 3.1 & 3.3 & 2.7 \\
\hline Family history of hypertension (\%) & 14.8 & 15 & 23.2 \\
\hline Family history of diabetes (\%) & 15.9 & 8.1 & 8.9 \\
\hline Body mass index $\left(\mathrm{kg} / \mathrm{m}^{2}\right)$, mean & $25.1( \pm 4.8)$ & $25.4( \pm 5.2)$ & $23.9( \pm 4.1)$ \\
\hline Waist-to-hip ratio, mean & $0.93( \pm 0.08)$ & $0.93( \pm 0.09)$ & $0.92( \pm 0.31)$ \\
\hline Waist circumference $(\mathrm{cm})$, mean & $89.7( \pm 10.3)$ & $92.7( \pm 13.7)$ & $85.9( \pm 10.5)$ \\
\hline Smoking (\%) & 34.3 & 35.8 & 49.1 \\
\hline Smokeless tobacco (\%) & 5.2 & 11.1 & 15.6 \\
\hline Exposure to 2ndhand tobacco (\%) & 40.7 & 49.7 & 46.7 \\
\hline Drinking alcohol (ever \%) & 20.1 & 3.1 & 7.8 \\
\hline Walk 7 days a week for at least 30 minutes a day (\%) & 81.1 & 85.9 & 77.2 \\
\hline Reported vigorous physical activity $\geq 1$ day in during last 7 days (\%) & 17.1 & 18.8 & 18.6 \\
\hline Reported moderate physical activity $\geq 1$ day in during last 7 days (\%) & 20.5 & 18.9 & 37.0 \\
\hline Blood pressure (BP) measurement (never \%) & 57.3 & 62.7 & 68.8 \\
\hline Hypertension (BP $\geq 140 / 90$ mm Hg or using antihypertensive drugs (\%) & 34.5 & 28.2 & 28.8 \\
\hline Physician diagnosed diabetes (\%) & 10.8 & 6.5 & 6.8 \\
\hline Glycosylated hemoglobin or $\mathrm{HbA} 1 \mathrm{c} \geq 6.5 \%$ & $5.8( \pm 1.1)$ & $5.7( \pm 1.7)$ & $5.9( \pm 1.3)$ \\
\hline
\end{tabular}




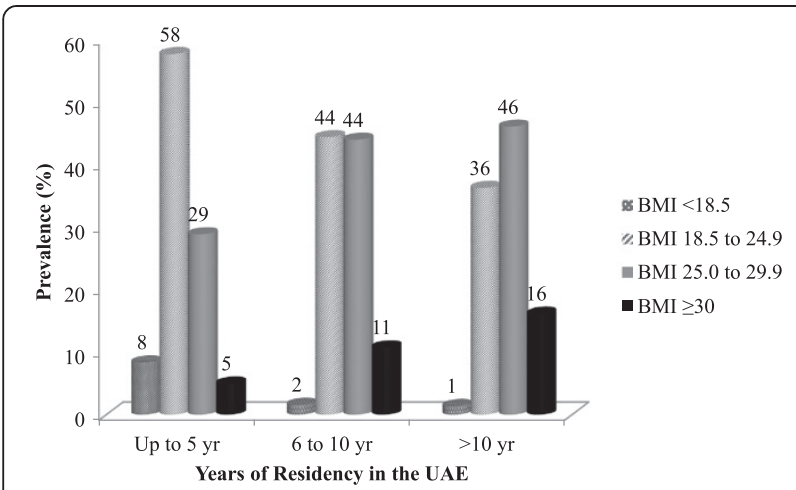

Figure 1 Prevalence of body mass index-derived estimates of underweight, normal weight, overweight and obesity by years of residency in the UAE for South Asian immigrants.

hypertension, smoking and diabetes (statistical analyses are not shown).

We did not find a significant $(\mathrm{p}<0.05)$ association of hypertension and cigarette smoking with living in the UAE for 6 to 10 years or more than 10 years. Diabetes was significantly associated with 10 or more years of residency in UAE. We did not find a significant relation of other lifestyle variables such as physical activity with duration of residency in UAE.

\section{Discussion}

The prevalence of overweight and obesity in our sample of South Asian immigrants living in the UAE was higher than published estimates from their home countries of India, Pakistan and Bangladesh. The mean BMI in our study was considerably higher compared to working men aged 20 to 59 years in India $\left(31.5 \mathrm{~kg} / \mathrm{m}^{2}\right.$ versus $\left.23.1 \mathrm{~kg} / \mathrm{m}^{2}\right)$ [25] and Bangladesh $\left(26.2 \mathrm{~kg} / \mathrm{m}^{2}\right.$ versus $19.7 \mathrm{~kg} / \mathrm{m}^{2}$ ) [26]. Prevalence of overweight and obesity in Pakistani immigrants was more than double compared to their counterparts in Pakistan $(50.5 \%$ versus 22.0\%) [27]. While the prevalence of overweight and obesity among South Asian immigrants living in UAE for more than 10 years $(62.7 \%)$ was substantially higher than the prevalence amongst their own non-migrant countrymen, obesity was relatively close to age-standardised prevalence rate for the native Emirati population (67.7\%) [28].

The prevalence of central obesity (63.4\%) in the study sample was higher compared to native Emirati men (58.6\%) [28], which is similar to results from other studies reporting high rates of central obesity (classified using the waist-tohip ratio) among South Asian immigrants [28,29]. Central obesity is an independent risk factor for cardiovascular disease in the Indian subcontinent male population [30]; this highlights the importance of measuring central obesity rather than body mass and height alone.

In our study population, the prevalence of overweight and obesity was significantly higher among those who had been living in the UAE for a longer period. Indeed, the prevalence of overweight and obesity increased from $34.8 \%$ with five years residency to $59.3 \%$ with 6 to 10 years residency and $62.3 \%$ with more than 10 years of residency. Previous studies indicate relatively lower rates of poor health among newly arrived South Asian immigrants in Europe and Canada compared to the general population [31]. However, it would appear that that this "immigrant health advantage" over the native population will decrease as the number of years lived in the host country rises $[32,33]$. Significant changes in diet amongst immigrants have been reported, with a substantial increase in overall energy and fat intake due to the accessibility and availability of energy-dense foods and snacks. Moreover, there is a switch from whole grains and pulses to more refined sources of carbohydrate along with increased consumption of soft drinks [32]. Our results are consistent with previous studies in which long-term immigrants reported higher rates of obesity, diabetes, hypertension and smoking compared to natives [34]. Study findings provide more evidence on the notion of a Healthy Migrant Effect seen in Western countries where upon arrival, immigrants are healthier than the native population, however, their health status declines as the duration of their stay increases $[31,32,34]$. The UAE has been previously defined as an obesogenic environment due to an accelerated nutrition transition moving away from traditional "healthy" foods and a high level of physical activity to an abundance of "unhealthy" energy-dense foods coupled with a sedentary life style [13]. The prolonged positive energy balance required to elicit high rates of obesity among South Asian immigrant males living in the UAE for five or more years may be due to dietary acculturation characterized by adopting affordable low quality food with high energy intake (primarily from refined sugar and saturated fat) with or without a concomitant reduction in daily energy expenditure (physical activity). It might be the reason for a positive association between diabetes and living in UAE for more than ten years.

Drivers, shopkeepers and tailors reported very low levels of moderate and vigorous physical activity. The prevalence of BMI-derived overweight and obesity, and central obesity estimates was very high among migrants working in sedentary occupations such as drivers, shop keepers and tailors, particularly those who had lived in the UAE for more than five years. These findings are in agreement with other studies that have reported low physical activity and high engagement in sedentary behaviour among South Asian immigrants [35].

There was a significant positive significant association between obesity and college or university level education. The direct association between income and education in developed countries may indicate healthier lifestyle choices in those with higher literacy, particularly those with higher 
Table 2 Prevalence and un-adjusted odds ratios of factors associated with overweight/obesity and central obesity, in male South Asian Immigrants, $(n=1,375)$ Al Ain, Abu Dhabi, UAE, 2012

\begin{tabular}{|c|c|c|c|c|c|c|c|c|}
\hline & & \multicolumn{4}{|l|}{ Overweight } & \multicolumn{3}{|c|}{ With central obesity } \\
\hline & & $\mathrm{BMI} \geq 25.0$ & Crude OR & $p$ value & & $\begin{array}{l}\text { Waist-to-hip } \\
\text { ratio } \geq 0.90 \mathrm{~cm}\end{array}$ & Crude OR & $p$ value \\
\hline Nationality & All & n (\%) & $(95 \% \mathrm{Cl})$ & & All & n (\%) & $(95 \% \mathrm{Cl})$ & \\
\hline India & 432 & $205(47.4)$ & $1.51(1.16-1.94)$ & 0.002 & 433 & $289(66.7)$ & $1.34(1.03-1.74)$ & 0.028 \\
\hline Pakistan & 383 & $201(52.5)$ & $1.84(1.42-2.40)$ & 0.000 & 383 & $248(64.7)$ & $1.23(0.93,-1.61)$ & 0.135 \\
\hline Bangladesh & 558 & $209(37.5)$ & 1.0 & & 559 & $335(59.9)$ & 1.0 & \\
\hline \multicolumn{9}{|l|}{ Age group $(n, \%)$} \\
\hline 18-35 years & 809 & $282(34.8)$ & 1.0 & & 810 & $417(51.5)$ & 1.0 & \\
\hline $36-45$ years & 307 & $182(59.3)$ & $2.72(2.07-3.56)$ & 0.000 & 307 & $244(79.5)$ & $3.65(2.67-4.97)$ & 0.000 \\
\hline $46+$ years & 199 & $124(62.3)$ & $3.08(2.24-4.26)$ & 0.000 & 200 & $174(87.0)$ & $6.31(4.08-9.74)$ & 0.000 \\
\hline \multicolumn{9}{|c|}{ Monthly salary in UAE Dirhams (AED), n, \% } \\
\hline Botom quartile & 370 & $103(27.8)$ & 1.0 & & 371 & $198(53.4)$ & 1.0 & \\
\hline Second quartile & 290 & $108(37.2)$ & $1.54(1.11-2.14)$ & 0.010 & 290 & $176(60.7)$ & $1.35(0.99-1.84)$ & 0.060 \\
\hline Third quartile & 399 & $219(54.9)$ & $3.15(2.33-4.26)$ & 0.000 & 399 & $275(68.9)$ & $1.94(1.44-2.60)$ & 0.000 \\
\hline Top quartile & 314 & $185(58.9)$ & $3.72(2.70-5.12)$ & 0.000 & 315 & $223(70.8)$ & $2.11(1.54-2.91)$ & 0.000 \\
\hline \multicolumn{9}{|l|}{ Education (n,\%) } \\
\hline No formal schooling & 172 & 55 (31.9) & 1.0 & & 173 & $98(56.6)$ & 1.0 & \\
\hline Primary or middle & 473 & $196(41.4)$ & $1.50(1.04-2.18)$ & 0.030 & 473 & $301(63.6)$ & $1.34(0.94-1.91)$ & 0.106 \\
\hline Secondary or high school & 585 & $283(48.4)$ & $1.99(1.39-2.85)$ & 0.000 & 586 & $387(66.0)$ & $1.49(1.05-2.10)$ & 0.024 \\
\hline College or university & 139 & $80(57.5)$ & $2.88(1.81-4.59)$ & 0.000 & 139 & $83(59.7)$ & $1.13(0.72-1.78)$ & 0.586 \\
\hline \multicolumn{9}{|l|}{ Occupation (n, \%) } \\
\hline Driver & 317 & $190(59.9)$ & $3.29(2.31-4.71)$ & 0.000 & 317 & $220(69.4)$ & $1.94(1.37-2.76)$ & 0.000 \\
\hline Laborer & 234 & $73(31.2)$ & 1.0 & & 234 & $137(58.5)$ & $1.21(0.84-1.74)$ & 0.301 \\
\hline Construction worker & 171 & $61(35.7)$ & $1.22(0.80-1.85)$ & 0.345 & 172 & $103(59.9)$ & $1.28(0.86-1.91)$ & 0.222 \\
\hline Agriculture worker & 235 & 79 (33.6) & $1.11(0.75-1.64)$ & 0.576 & 236 & $127(53.8)$ & 1.0 & \\
\hline Salesman & 79 & $38(48.1)$ & $2.04(1.21-3.44)$ & 0.007 & 79 & $52(65.8)$ & $1.65(0.97-2.81)$ & 0.063 \\
\hline Professional, office worker & 95 & $52(54.7)$ & $2.66(1.63-4.34)$ & 0.000 & 95 & $63(66.3)$ & $1.68(1.02-2.77)$ & 0.038 \\
\hline Business/shop keeper & 60 & $40(66.7)$ & $4.41(2.41-8.07)$ & 0.000 & 60 & 49 (81.7) & $3.82(1.89-7.72)$ & 0.000 \\
\hline Hospitality worker & 71 & $28(39.4)$ & $1.43(0.82-2.49)$ & 0.197 & 71 & $47(66.2)$ & $1.68(0.96-2.92)$ & 0.066 \\
\hline Tailor & 70 & $36(51.4)$ & $2.33(1.35-4.02)$ & 0.002 & 70 & $47(67.1)$ & $1.75(1.00-3.07)$ & 0.049 \\
\hline Other & 40 & $18(45.0)$ & $1.80(0.91-3.57)$ & 0.090 & 40 & $26(65.0)$ & $1.59(0.79-3.20)$ & 0.191 \\
\hline \multicolumn{9}{|l|}{ Type of accommodation } \\
\hline Shared with non-relatives & 716 & $314(43.8)$ & $1.63(1.14-2.33)$ & 0.007 & 717 & $459(64.0)$ & $1.40(0.99-1.97)$ & 0.053 \\
\hline Shared with family & 152 & $82(53.9)$ & $2.45(1.55-3.86)$ & 0.000 & 152 & 91 (59.9) & $1.17(0.75-1.83)$ & 0.479 \\
\hline Single accommodation & 153 & $89(58.2)$ & $2.91(1.84-4.59)$ & 0.000 & 153 & $113(73.8)$ & $2.22(1.38-3.56)$ & 0.001 \\
\hline Live with sponsor & 184 & $76(41.3)$ & $1.47(0.95-2.28)$ & 0.083 & 184 & $114(61.9)$ & $1.28(0.83-1.96)$ & 0.253 \\
\hline Live in a labor camp & 167 & $54(32.3)$ & 1.0 & & 168 & $94(55.9)$ & 1.0 & \\
\hline \multicolumn{9}{|l|}{ Home country setting } \\
\hline Rural & 930 & $381(40.9)$ & 1.0 & & 932 & $575(61.7)$ & 1.0 & \\
\hline Urban or semi-urban & 426 & $228(53.5)$ & $1.66(1.32-2.09)$ & 0.000 & 426 & $285(66.9)$ & $1.25(0.99-1.59)$ & 0.065 \\
\hline \multicolumn{9}{|l|}{ Length of stay in UAE } \\
\hline 1 to 5 years & 546 & $187(34.2)$ & 1.0 & & 547 & $287(54.5)$ & 1.0 & \\
\hline 6 to 10 years & 257 & $139(54.1)$ & $2.26(1.67-3.06)$ & 0.000 & 257 & $182(70.8)$ & $2.19(1.60-3.02)$ & 0.000 \\
\hline$>10$ years & 413 & $259(62.7)$ & $3.23(2.47-4.21)$ & 0.000 & 414 & $346(83.6)$ & $4.61(3.38-6.28)$ & 0.000 \\
\hline
\end{tabular}


Table 2 Prevalence and un-adjusted odds ratios of factors associated with overweight/obesity and central obesity, in male South Asian Immigrants, ( $=1$,375) Al Ain, Abu Dhabi, UAE, 2012 (Continued)

\begin{tabular}{|c|c|c|c|c|c|c|c|c|}
\hline \multicolumn{9}{|c|}{ Marital status } \\
\hline Single & 411 & $118(28.7)$ & 1.0 & & 412 & $178(43.2)$ & 1.0 & \\
\hline Married & 962 & $497(51.7)$ & $2.65(2.07-3.40)$ & 0.000 & 963 & $694(72.1)$ & $3.39(2.66-4.31)$ & 0.000 \\
\hline \multicolumn{9}{|c|}{ Smoking ever } \\
\hline Never & 826 & $361(43.7)$ & 1.0 & & 827 & $510(61.7)$ & 1.0 & \\
\hline Ever & 547 & $254(46.4)$ & $1.12(0.89-1.38)$ & 0.319 & 548 & $362(66.1)$ & $1.21(0.96-1.51)$ & 0.098 \\
\hline \multicolumn{9}{|c|}{ Smokeless tobacco (n, \%) } \\
\hline Never & 1160 & $514(44.3)$ & 1.0 & & 1162 & $735(63.2)$ & 1.0 & \\
\hline Ever & 150 & $76(50.7)$ & $1.29(0.91-1.81)$ & 0.142 & 150 & $97(64.7)$ & $1.06(0.74-1.52)$ & 0.735 \\
\hline \multicolumn{9}{|c|}{ Drinking alcohol } \\
\hline Never & 1118 & $490(43.8)$ & 1.0 & & 1119 & $696(62.2)$ & 1.0 & \\
\hline \multicolumn{9}{|c|}{ Walk for at least 30 minutes daily } \\
\hline Yes & 1016 & $449(44.2)$ & 1.0 & & 1018 & $636(62.5)$ & 1.0 & \\
\hline No & 314 & $151(48.1)$ & $1.17(0.91-1.51)$ & 0.225 & 314 & $209(66.5)$ & $1.19(0.91-1.56)$ & 0.189 \\
\hline \multicolumn{9}{|c|}{ Hypertension (BP $\geq 140 / 90$ mm Hg) } \\
\hline No & 955 & $367(38.4)$ & 1.0 & & 956 & $537(56.2)$ & 1.0 & \\
\hline Yes & 418 & $248(59.3)$ & $2.33(1.84-2.95)$ & 0.000 & 419 & $335(79.9)$ & $3.11(2.37-4.08)$ & 0.000 \\
\hline \multicolumn{9}{|l|}{ Diabetic } \\
\hline No & 1260 & $556(44.1)$ & 1.0 & & 1261 & 775 (61.5) & 1.0 & \\
\hline Yes & 113 & $59(52.2)$ & $1.38(0.94-2.03)$ & 0.100 & 114 & $97(85.1)$ & $3.58(2.11-6.06)$ & 0.000 \\
\hline
\end{tabular}

health literacy [36]. Further research is needed to elucidate whether this discrepancy may be due to factors such as poorer health literacy level [37].

An alarming finding is that almost $76 \%$ of study participants with hypertension and 44\% with diabetes were not aware of their conditions. Compared to white Caucasians, South Asians report overall lower disease awareness: language barriers, religious and sociocultural factors have been attributed to poor awareness and late diagnosis $[37,38]$. Therefore, the treatment and control of hypertension and diabetes is crucial for reducing cardiovascular death rates as the study population is already prone to developing coronary heart disease at a younger age $(<40$ years in men) $[5,6,8]$. Greater emphasis on improving primary health care and health education in this population may increase awareness and promote healthy lifestyles has the potential to improve cardiovascular health.

\section{Strengths and limitations}

There are several strengths of this study. At present, to the best of our knowledge, this is the first study documenting the burden of obesity in South Asian male immigrants living in the UAE. We recruited a large random representative sample (with a good response rate $76.4 \%$ ) from the mandatory health visa screening centre in the second largest city in the emirate of Abu Dhabi in the UAE. In addition, we utilized an adapted version of the WHO STEPwise questionnaire for NCD risk factor surveillance, two anthropometric indices to classify obesity in our population (BMI and WHR) and objectively measured blood pressure, and also HbAlc (in a sub-sample of our study population). However, there are some limitations inherent in the study design which means the data should be interpreted with caution. Firstly, as with any cross sectional design, it is not possible to draw firm conclusions about the temporal or causal nature of the association between acculturation, various risk factors and obesity. Secondly, we did not use a standardized acculturation scale; rather, we used years of residency as a surrogate measure. Currently, there are no validated multidimensional instruments to measure acculturation among South Asians in the UAE. Future studies may want to consider employing modified versions of standardized and validated acculturation scales that have been used in South Asian immigrant populations in the United Kingdom [39] and the United States [40]. Alternatively, researchers could develop a contextual- and culturally-specific acculturation scale for use in migrant populations in the UAE that would include specific acculturation domains such as dietary preferences, clothing style, use of own-culture media, 
Table 3 Multivariable logistic regression: adjusted odds ratios of factors associated with Overweight/obesity and Central obesity in male South Asian immigrants ( $n=1,375)$ Al Ain, Abu Dhabi, UAE, 2012

\begin{tabular}{|c|c|c|c|c|}
\hline & $\begin{array}{l}\text { Overweight } \\
\text { AOR }\end{array}$ & $p$ value & $\begin{array}{l}\text { Central obesity } \\
\text { AOR }\end{array}$ & $p$ value \\
\hline Nationality & $(95 \% \mathrm{Cl})$ & & $(95 \% \mathrm{Cl})$ & \\
\hline India & $0.91(0.65-1.27)$ & 0.602 & $0.88(0.62-1.27)$ & 0.483 \\
\hline Pakistan & $1.48(0.98-2.24)$ & 0.066 & $1.06(0.73-1.55)$ & 0.747 \\
\hline Bangladesh & 1.0 & & 1.0 & \\
\hline Age, Years & $1.02(0.99-1.04)$ & 0.065 & $1.06(1.03-1.08)$ & $<0.001$ \\
\hline Monthly salary in UAE Dirhams (AED) & $1.00(0.99-1.00)$ & 0.735 & $0.99(0.99-1.00)$ & 0.598 \\
\hline \multicolumn{5}{|l|}{ Education } \\
\hline None & 1.0 & & 1.0 & \\
\hline Primary or middle & $1.51(0.95-2.41)$ & 0.083 & $1.58(0.98-2.55)$ & 0.058 \\
\hline Secondary or high school & $1.54(0.96-2.49)$ & 0.075 & $1.27(0.78-2.05)$ & 0.340 \\
\hline College or university & $2.05(1.03-4.06$ & 0.040 & $1.09(0.55-2.23)$ & 0.808 \\
\hline \multicolumn{5}{|l|}{ Occupation } \\
\hline Driver & $2.54(1.65-3.89)$ & $<0.001$ & $1.57(0.99-2.48)$ & 0.051 \\
\hline Laborer & 1.0 & & $1.21(0.76-1.94)$ & 0.416 \\
\hline Construction worker & $1.08(0.66-1.78)$ & 0.745 & $1.29(0.76-2.20)$ & 0.333 \\
\hline Agriculture worker & $1.16(0.73-1.83)$ & 0.523 & 1.0 & \\
\hline Salesman & $1.45(0.76-2.74)$ & 0.253 & $1.81(0.87-3.75)$ & 0.110 \\
\hline Professional, office worker & $1.85(0.96-3.56)$ & 0.066 & $2.14(1.02-4.47)$ & 0.043 \\
\hline Business man/shop keeper & $2.35(1.08-5.08)$ & 0.030 & $3.05(1.20-7.73)$ & 0.019 \\
\hline Hospitality worker & $1.58(0.82-3.02)$ & 0.170 & $1.38(0.68-2.79)$ & 0.361 \\
\hline Tailor & $3.33(1.63-6.83)$ & $<0.001$ & $1.98(0.89-4.36)$ & 0.091 \\
\hline Other & $1.18(0.52-2.68)$ & 0.687 & $1.14(0.46-2.83)$ & 0.764 \\
\hline \multicolumn{5}{|l|}{ Type of accommodation } \\
\hline Shared with non-relatives & $1.20(0.78-1.83)$ & 0.339 & $1.07(0.70-1.64)$ & 0.737 \\
\hline Shared with family & $1.45(0.80-2.63)$ & 0.213 & $0.78(0.42-1.45)$ & 0.434 \\
\hline Single accommodation & $1.69(0.97-2.94)$ & 0.062 & $1.43(0.78-2.62)$ & 0.246 \\
\hline Live with sponsor & $1.02(0.63-1.73)$ & 0.932 & $0.78(0.45-1.34)$ & 0.377 \\
\hline Live in a labor camp & 1.0 & & 1.0 & \\
\hline \multicolumn{5}{|l|}{ Home country setting } \\
\hline Rural & 1.0 & & 1.0 & \\
\hline Urban or semi-urban & $1.23(0.91-1.64)$ & 0.170 & $1.05(0.76-1.46)$ & 0.731 \\
\hline \multicolumn{5}{|l|}{ Length of stay in UAE } \\
\hline 1 to 5 years & 1.0 & & 1.0 & \\
\hline 6 to 10 years & $1.81(1.28-2.57)$ & $<0.001$ & $1.63(1.13-2.35)$ & 0.008 \\
\hline$>10$ years & $1.69(1.15-2.48)$ & 0.007 & $1.95(1.26-3.01)$ & 0.002 \\
\hline \multicolumn{5}{|l|}{ Marital status } \\
\hline Single & 1.0 & & 1.0 & \\
\hline Married & $1.35(0.96-1.90)$ & 0.080 & $1.34(0.95-1.88)$ & 0.086 \\
\hline \multicolumn{5}{|l|}{ Hypertension (BP $\geq 140 / 90$ mm Hg) } \\
\hline No & 1.0 & & 1.0 & \\
\hline Yes & $1.87(1.40-2.48)$ & $<0.001$ & $2.07(1.49-2.87)$ & $<0.001$ \\
\hline \multicolumn{5}{|l|}{ Diabetes } \\
\hline No & 1.0 & & 1.0 & \\
\hline Yes & $0.78(0.52-1.55)$ & 0.196 & $1.05(0.44,1.89)$ & 0.671 \\
\hline
\end{tabular}


language use and fluency, social connections, and cultural/ religious beliefs. Thirdly, we recruited the sample in the visa screening center in Al Ain, Abu Dhabi emirate and the study sample may thus not represent the South Asian male population residing in other emirates in the UAE. However, we would not expect the socioeconomic and lifestyle characteristics of our sample to differ greatly from South Asians in other emirates. The large sample size provides sufficient power to evaluate differences in the dependent variables by socio-demographic and lifestyle variables. Finally, it should be noted that our study results may be specific to migrant men and may not translate to South Asian women.

\section{Conclusions}

This is the first study to reveal a high prevalence of overweight, obesity, hypertension and diabetes among a relatively young South Asian male immigrant population living in the UAE. Study findings suggest a diminished 'Healthy Migrant Effect' with increased years of residency possibly due to greater acculturation (particularly greater than five years residency) and a transition in lifestyle behaviors. Preventive health measures are often ignored in this population. Culturally-tailored health education interventions targeting the maintenance of a healthy body size, coupled with regular assessments of glucose control and blood pressure are urgently required in this population. The design, development, and implementation of future health promotion campaigns, interventions, and strategies amongst South Asians must consider the sociocultural, religious, ethnic, and educational diversity of this population.

\section{Abbreviations}

AED: Emirati Dirham; BMI: Body mass index; Cl: Confidence interval; HbA1c: Glycated hemoglobin; NCD: Non-communicable chronic diseases; UAE: United Arab Emirates; USD: United States Dollar; WHO: World Health Organization; WC: Waist circumference; WHR: Waist-to-hip ratio.

\section{Competing interests}

The authors declare that they have no competing interests.

\section{Authors' contributions}

SS, RA, TL, and IB designed the study, IE and SD led the data collection, SS and HV led the data analysis and interpretation, SS and TL drafted the manuscript, and all authors critically reviewed, provided intellectual input to the manuscript and approved the final version of the manuscript.

\section{Acknowledgements}

This work was supported by the United Arab Emirates University (Grant No. NP09-30). We would like to thank all participants and investigators in this study.

\footnotetext{
Author details

${ }^{1}$ Institute of Public Health, College of Medicine and Health Sciences, United Arab Emirates University, Al Ain, United Arab Emirates. ${ }^{2}$ Ambulatory Health Services, SEHA, Al Ain, United Arab Emirates. ${ }^{3}$ School of Public Health, College of Nutrition and Pharmacy, University of Saskatchewan, Saskatchewan, Canada. ${ }^{4}$ Department of Pathology, College of Medicine and Health Sciences, United Arab Emirates University, Al Ain, United Arab Emirates.
}

Received: 1 December 2014 Accepted: 17 February 2015

Published online: 28 February 2015

\section{References}

1. World Health Organization: Foreword to the 2008-2013 Action Plan for the Global Strategy for the Prevention and Control of Noncommunicable Diseases. [http://www.who.int/nmh/publication/ncd_report2010/en/]

2. Bloom DE, Cafiero ET, Jané-Llopis E, Abrahams-Gessel S, Bloom LR, Fathima S, Feigl AB, Gaziano T, Mowafi M, Pandya A, Prettner K, Rosenberg L, Seligman B, Stein AZ, Weinstein C: The global economic burden of noncommunicable diseases. Geneva: World Economic Forum; 2011. Available at: http://www3. weforum.org/docs/WEF_Harvard_HE_GlobalEconomicBurdenNonCommunicableDiseases_2011.pdf. Accessed 30 November 2014.

3. Yusuf S, Reddy S, Ounpuu S, Anand S. Global burden of diseases: part 1: general considerations, the epidemiologic transition, risk factors, and impact of urbanization. Circulation. 2001;104(22):2746-53.

4. Reddy KS. Cardiovascular diseases in non-Western countries. N Engl J Med. 2004;350(24):2438-40.

5. Joshi P, Islam S, Pais P, Reddy S, Dorairaj P, Kazmi K, et al. Risk factors for early myocardial infarction in South Asian compared with individuals in other countries. JAMA. 2007;297(3):286-94.

6. Hodge AM, Dowse GK, Collins VR, Alberti KG, Gareeboo H, Tuomilehto J, et al. Abdominal fat distribution and insulin levels only partially explain adverse cardiovascular risk profile in Asian Indians. J Cardiovasc Risk. 1996;3(3):263-70.

7. McKeigue PM, Miller GJ, Marmot MG. Coronary heart disease in South Asians overseas: a review. J Clin Epidemiol. 1989;42(7):597-609.

8. Harding S. Mortality of migrants from the Indian subcontinent to England and Wales: effect of duration of residence. Epidemiology. 2003;14(3):287-92.

9. Narayan KM, Ali MK, Koplan JP. Global noncommunicable diseases - where worlds meet. N Engl J Med. 2010;363(13):1196-8.

10. World Health Organization Expert Consultation. Appropriate body-mass index for Asian populations and its implications for policy and intervention strategies. Lancet. 2004;363(9403):157-63.

11. Gray LJ, Yates T, Davies MJ, Brady E, Webb DR, Sattar N, et al. Defining obesity cut-off points for migrant South Asians. PLoS One. 2011;6(10):e26464.

12. Delavari M, Sønderlund AL, Swinburn B, Mellor D, Renzaho A. Acculturation and obesity among migrant populations in high income countries-a systematic review. BMC Public Health. 2013;13:458.

13. Ng SW, Zaghloul S, Ali H, Harrison G, Yeatts K, El Sadig M, et al. Nutrition transition in the United Arab Emirates. Eur J Clin Nutr. 2011;65(12):1328-37.

14. Al Junaibi AA, Abdulle A, Sabri S, Hag-Ali M, Nagelkerke N. The prevalence and potential determinants of obesity among school children and adolescents in Abu Dhabi. United Arab Emirates Int J Obes. 2013;37(1):68-74.

15. Walpole SC, Prieto-Merino D, Edwards P, Cleland J, Stevens G, Roberts I. The weight of nations: an estimation of adult human biomass. BMC Public Health. 2012;12:439.

16. United Arab Emirates Ministry of Economy: Preliminary results of population, housing, and establishment Census 2005 [http://www.cscc.unc.edu/uaee/ public/UNLICOMMUAE2005CensusResults07282008.pdf]

17. Abu Dhabi Health Services Company. Statistical Summary Report for Application Summary by Nationalities, Professions and Gender, From January 1 to December 31, 2012. Al Ain, Abu Dhabi: Disease Prevention and Screening Centre, Preventive Medicine Department; 2012.

18. Al-Maskari F, Shah SM, Al-Sharhan R, Al-Haj E, Al-Kaabi K, Khonji D, et al. Prevalence of depression and suicidal behaviours among male migrant workers in United Arab Emirates. J Immigr Minor Health. 2011;13(6):1027-32.

19. World Health Organization. The WHO STEPwise Approach to Chronic Disease Risk Factor Surveillance. Geneva, Switzerland: World Health Organization; 2014. Available at: http://www.who.int/chp/steps/resources/ updates/en/.

20. International Physical Activity Questionnaire (IPAQ): Guidelines for data processing and analysis of the International Physical Activity Questionnaire (IPAQ)-short and long forms. [http://www.institutferran.org/documentos/ scoring_short_ipaq_april04.pdf]

21. World Health Organization. Obesity: preventing and managing the global epidemic. Report of a WHO consultation. World Health Organ Tech Rep Ser. 2000;894:1-253.

22. World Health Organization: Waist circumference and waist-hip ratio: report of a WHO expert consultation. [http://apps.who.int/iris/bitstream/10665/ 44583/1/9789241501491_eng.pdf] 
23. 1999 World Health Organization-International Society of Hypertension Guidelines for the Management of Hypertension. Guidelines Subcommittee. J Hypertens. 1999;17(2):151-83.

24. Chobanian AV, Bakris GL, Black HR, Cushman WC, Green LA, Izzo Jr JL, et al. Joint National Committee on Prevention, Detection, Evaluation, and Treatment of High Blood Pressure. National Heart, Lung, and Blood Institute; National High Blood Pressure Education Program Coordinating Committee: Seventh report of the Joint National Committee on Prevention, Detection, Evaluation, and Treatment of High Blood Pressure. Hypertension. 2003;42(6):1206-52.

25. Reddy KS, Prabhakaran D, Chaturvedi V, Jeemon P, Thankappan KR, Ramakrishnan $\mathrm{L}$, et al. Methods for establishing a surveillance system for chronic diseases in Indian Industrial population. Bull World Health Organ 2006;84(6):461-9.

26. Hussain A, Vaaler S, Sayeed MA, Mahtab H, Ali SM, Khan AK. Type 2 diabetes and impaired fasting blood glucose in rural Bangladesh: a population-based study. Eur J Public Health. 2007:17(3):291-6.

27. Jafar TH, Chaturvedi, Pappas G. Prevalence of overweight and obesity and their association with hypertension, and diabetes mellitus in an Indo-Asian population. CMAJ. 2006;175(9):1071-7.

28. Hajat C, Harrison O, Al Siksek Z. Weqaya: a population-wide cardiovascular screening program in Abu Dhabi, United Arab Emirates. Am J Public Health. 2012;102(25):909-14.

29. Fernandez R, Miranda C, Everett B. Prevalence of obesity among migrant Asian Indians: a systematic review and meta-analysis. Int J Evid Based Healthc. 2011;9(4):420-8.

30. Kumar BN, Meyer HE, Wandel M, Dalen I, Holmboe-Ottesen G. Ethnic differences in obesity among immigrants from developing countries in Oslo. Norway Int J Obes. 2006;30(4):684-90.

31. Prasad DS, Kabir Z, Dash AK, Das BC. Abdominal obesity, an independen cardiovascular risk factor in Indian subcontinent: a clinic epidemiological evidence summary. J Cardiovasc Dis Res. 2011;2(4):199-205.

32. Holmboe-Ottesen $\mathrm{G}$, Wandel $\mathrm{M}$ : Changes in dietary habits after migration and consequences for health: a focus on South Asians in Europe. Food Nutr Res 2012, 56. Doi:10.3402/fnr.v56i0. 18891.

33. Kim IH, Carrasco C, Muntaner C, McKenzie K, Noh S. Ethnicity and post migration health trajectory in new immigrants to Canada. Am J Public Health. 2013;103(4):e96-104.

34. Uretsky MC, Mathiesen SG. The effects of years lived in the United States on the general health status of California's foreign-born populations. J Immigr Minor Health. 2007;9(2):125-36.

35. Chiu M, Austin PC, Manuel DG, Tu JV. Cardiovascular risk factor profiles of recent immigrants vs long-term residents of Ontario: a multi-ethnic study. Can J Cardiol. 2012;28(1):20-6.

36. Jonnalagadda S, Diwan S. Regional variation in dietary intake and body mass index of first generation-Indian immigrants in the United States. J Am Diet Assoc. 2002;102(9):1286-9.

37. Popkin BM. What is unique about the experience in lower- and middleincome less-industrialised countries compared with the very-high income countries? The shift in the stages of the nutrition transition differs from past experiences. Public Health Nutr. 2002;5(1 A):205-14.

38. Misra A, Khurana L. Obesity-related non-communicable diseases: South Asians vs White Caucasians. Int J Obes. 2011;35(2):167-87.

39. Palmer B, Macfarlane G, Afzal C, Esmail A, Silman A, Lunt M. Acculturation and the prevalence of pain amongst South Asian minority ethnic groups in the UK. Rheumatology. 2007;46(6):1009-14.

40. Kanaya A, Ewing S, Vittinghoff E, Herrington D, Tegeler C, Mills C, et al. Acculturation and Subclinical Atherosclerosis among U.S. South Asians: findings from the MASALA study. J Clin Exp Res Cardiol. 2014;1 (1):102.

\section{Submit your next manuscript to BioMed Central and take full advantage of:}

- Convenient online submission

- Thorough peer review

- No space constraints or color figure charges

- Immediate publication on acceptance

- Inclusion in PubMed, CAS, Scopus and Google Scholar

- Research which is freely available for redistribution 